\title{
HeS \\ A Comprehensive Study of Black Phosphorus-Graphite Composite Anodes and HEMM Synthesis Conditions for Improved Cycle Stability
}

\author{
Hosop Shin, ${ }^{1, *, a}$ Jianyu Zhang, ${ }^{1}$ and Wei Lu $\oplus^{1,2, z}$ \\ ${ }^{1}$ Department of Mechanical Engineering, University of Michigan, Ann Arbor, Michigan 48109, USA \\ ${ }^{2}$ Department of Materials Science and Engineering, University of Michigan, Ann Arbor, Michigan 48109, USA
}

Black phosphorus (BP) is a high capacity anode material and has been synthesized with different carbon materials to mitigate volume changes during lithiation/delithiation. There is a large discrepancy in cycle stability of phosphorus-carbon materials in the literature, and factors affecting cycle performance are not well elucidated. In this study, the electrochemical performance of a black phosphorusgraphite (BP-G) composite anode material with regards to (1) material composition, (2) electrolyte additive, (3) ballmilling synthesis conditions, and (4) electrode loading is thoroughly investigated. In particular, this study reveals how ballmilling synthesis conditions correlate to electrochemical performance. Results show that the main contributors to cycle stability of BP-G composites are material composition and electrode loading, while first cycle efficiency and reversible capacity are strongly dependent on ballmilling synthetic conditions. Composition control is the most effective way to mitigate the volume change-induced mechanical degradation of BP-G composites, while ballmilling processing optimization is the main contributor to BP activation in BP-G composites, improving reversible capacity and first cycle efficiency. We thereby propose an optimized, HEMM-based synthetic route for improved BP-G materials. This study provides a comprehensive understanding of BP-G electrochemical performance and the correlation to HEMM synthesis conditions.

(C) The Author(s) 2019. Published by ECS. This is an open access article distributed under the terms of the Creative Commons Attribution 4.0 License (CC BY, http://creativecommons.org/licenses/by/4.0/), which permits unrestricted reuse of the work in any medium, provided the original work is properly cited. [DOI: $10.1149 / 2.1421912 \mathrm{jes}]$

(cc) BY

Manuscript submitted June 3, 2019; revised manuscript received July 23, 2019. Published August 5, 2019.

Black phosphorus (BP) is an attractive, next-generation anode material with a high theoretical specific capacity of $2,596 \mathrm{mAh} / \mathrm{g}$, significantly higher than those of current generation anodes used in lithium-ion batteries. BP is one of three main phosphorus allotropes including white $\mathrm{P}$ (WP) and red $\mathrm{P}(\mathrm{RP})$, and is thermodynamically the most stable, chemically the least reactive, and less flammable than its counterparts, with relatively high electronic conductivity compared to other phosphorus allotropes. ${ }^{1}$ BP possesses a puckered layer structure similar to graphite but with a larger interlayer space $(0.54 \mathrm{~nm})$ that can accommodate large ions such as sodium. For this reason, it has also garnered a great deal of attention as an anode candidate for sodium-ion batteries. $^{2-6}$

Despite BP potential as an alternative anode material, three main challenges have prevented its use in rechargeable batteries. First, a scalable and energy-efficient synthesis and processing technique that can reliably produce high-quality BP has yet to be established. High pressures and temperatures are required to generate BP from WP or $\mathrm{RP}$, and synthesis must take place in an inert atmosphere and be precisely controlled due to safety issues. ${ }^{6,7}$ Although several methods have been developed for BP production, these techniques use toxic chemicals and complex apparatuses, are time-consuming, and only produce small amounts of BP. ${ }^{6}$ Second, in general, the electronic conductivity of synthesized BP is not sufficient for use as an electrode material. An ideal BP must exhibit moderate electronic conductivity $\left(0.2 \sim 3.3 \times 10^{2} \mathrm{~S} / \mathrm{m}\right)$ greater than silicon $\left(10^{-3} \mathrm{~S} / \mathrm{m}\right)$ but less than graphite $\left(3.3 \times 10^{2} \sim 2 \times 10^{5} \mathrm{~S} / \mathrm{m}\right){ }^{8}$ The electronic conductivity of BP depends upon its crystalline form (orthorhombic, rhombohedral, or simple cubic), as well as its quality. ${ }^{7,9}$ High-energy mechanical milling (HEMM), widely used in composite material synthesis, will produce BP; the difficulty lies in synthesizing high-quality BP with moderate electronic conductivity. ${ }^{1,10}$ Electrochemical activity of BP has thus been typically poor, with lower reversible capacity than theoretical capacity. ${ }^{1,10}$ Finally, BP undergoes significant volume changes during lithiation/delithiation, causing particle pulverization or fracture. This volume change thereby leads to a loss of electrical contact, resulting in significant capacity fade in BP-based anodes. Although the

*Electrochemical Society Member.

${ }^{\text {a }}$ Present address: Department of Mechanical and Energy Engineering, Indiana University-Purdue University Indianapolis, Indianapolis, Indiana 46202, USA.

zE-mail:weilu@umich.edu percent volume change for orthorhombic BP transformed to hexagonal $\mathrm{Li}_{3} \mathrm{P}$ is theoretically $307 \%,{ }^{8}$ a recent in-situ transmission electron microscopy (TEM) study revealed that BP experiences an anisotropic volume change of $77 \%$ upon delithiation, although not lithiation. ${ }^{18}$

In order to overcome the low electrical conductivity and large volume change issues associated with BP, BP- or phosphorus-based anodes have been synthesized in the form of composite materials in which nano-sized BP is combined with carbon. ${ }^{1,8,11-17,19,20}$ Park et al. was the first to implement HEMM to synthesize BP-C (Super P) composites; however, these composites demonstrated dramatic capacity loss in less than 30 cycles when the cell was cycled over the full voltage window $(0-2 \mathrm{~V}) .{ }^{1}$ This trend of dramatic capacity fade was also reported by another study wherein an RP-graphite composite was synthesized using HEMM. ${ }^{16}$ Another research group synthesized RP-porous carbon using a vaporization/adsorption technique and produced similar results, suggesting that the nature of carbon and $\mathrm{P}-\mathrm{C}$ composition determines the electrochemical performance. ${ }^{11}$ Similar results were also observed for RP-encapsulated carbon nanotubes. ${ }^{20}$ Conversely, four other studies reported that their composites, synthesized by HEMM or vaporization/adsorption, had exceptionally high capacity retention over 100 cycles with high reversible capacities. $^{8,12,13,19}$ While one group emphasized the importance of ballmilling time for improved cycle performance, ${ }^{12}$ the other three groups suggested that electrochemical performance depended upon carbon materials. ${ }^{8,13,19}$ In particular, Sun et al. suggested that the excellent electrochemical performance of their BP-graphite anode was due to the formation of robust $\mathrm{P}-\mathrm{C}$ bonds originating from the graphite. ${ }^{8}$

Results regarding the electrochemical performances of phosphorus-carbon composites thereby have been inconclusive. ${ }^{16}$ While some researchers have reported significant capacity fade and poor first cycle coulombic efficiency of their P-C composites, $1,11,13,14,16,20$ others have demonstrated moderate or excellent cycle performance and relatively high first cycle coulombic efficiency. ${ }^{8,12,13,15,19}$ Several reasons might underlie these discrepancies. First, the reported capacity of P-C composites was defined differently, either based on the weight of phosphorus itself or the total weight of phosphorus and carbon. As a result, the rates of cycling and active material loading are not comparable to one another. Second, different synthesis methods and synthesis variables were used to generate these P-C composites. Third, carbon sources and the properties of the initial carbon and BP varied. Finally, different electrolytes, electrode composition, and active material loadings 
were used for cell testing. As such, direct comparison of results from these studies is not possible, and a lack of understanding as to the origin of significant differences in the electrochemical performances of different P-C composites persists. Moreover, dominant factors affecting the cycle stability of P-C composites remain in question and have yet to be assessed or confirmed quantitatively. This study thereby systematically investigates the electrochemical performance of a phosphorus-carbon material according to a set of specific factors.

The main goals of this work are to improve our understanding of the factors that influence the electrochemical performance of P-C composites and develop a framework for designing optimal BP-based anode materials using HEMM synthesis. To achieve the objectives, we evaluated the influence of 1) material composition, 2) electrolyte additive, and 3) HEMM synthesis on BP-graphite (BP-G) electrochemical performance, focusing on cycle stability, first cycle coulombic efficiency, and reversible capacity. We also addressed the correlation between the HEMM synthesis process and BP-G composite electrochemical performance to propose an optimized ballmilling approach.

\section{Experimental}

BP and BP-G composite synthesis.-BP powder was prepared by HEMM using a shaker-type milling machine (SPEX, 8000M mixer/mill) in an Ar-filled glove box. $6 \mathrm{~g}$ of RP (100 mesh, 98.9\% purity, Alfa Aesar) was added to a $65 \mathrm{~mL}$ hardened steel cylindrical vial with 28 hardened steel balls ( 10 balls with a diameter of $12.7 \mathrm{~mm}$ and 18 balls with a diameter of $6.35 \mathrm{~mm}$ ), and was ball-milled for $6 \mathrm{~h}$ for BP synthesis. The ball-to-powder mass ratio was 17:1. For BP-G composite synthesis, synthesized BP was placed into the same vial (65 mL) with graphite powder (Timrex SLP30, Timcal) and the same set of hardened steel balls. HEMM was carried out in an Ar-filled glove box using the same shaker mixer/mill with a ball-to-powder mass ratio of 25:1. Different ballmilling times were used to synthesize the BP-G composites. BP-G composites with different molar ratios were prepared: low BP-ratio $\left(\mathrm{BP}_{0.3} \mathrm{G}_{1} ; \mathrm{BP}, 43.6 \mathrm{wt} \%\right.$; graphite, $\left.56.4 \mathrm{wt} \%\right)$, high BP-ratio $\left(\mathrm{BP}_{0.9} \mathrm{G}_{1} ; \mathrm{BP}, 69.9 \mathrm{wt} \%\right.$; graphite, $\left.30.1 \mathrm{wt} \%\right)$, and half BP-ratio $\left(\mathrm{BP}_{0.5} \mathrm{G}_{1}\right.$; $\mathrm{BP}, 50 \mathrm{wt} \%$; graphite, $\left.50 \mathrm{wt} \%\right)$. To reduce the BP-G particle size and disperse agglomerated particles, synthesized BP-G powders were wet ball-milled at $3000 \mathrm{rpm}$ for 30 min with 15 zirconium oxide balls ( $5 \mathrm{~mm}$ diameter) and $\mathrm{N}$-methyl-2-pyrrolidone (NMP) using a dual asymmetric centrifuge-type SpeedMixer (FlackTek Inc.) after BP-G HEMM synthesis. We also designed a multistep ballmilling process using two different milling modes, shaker mill and planetary mill, to achieve the same goal. Specifically, before BP-G HEMM synthesis, BP and graphite were subject to planetary ballmilling (PBM) for $12 \mathrm{~h}$ (with $10 \mathrm{~min}$ rest every $50 \mathrm{~min}$ ) to reduce the particle size.

Electrode preparation and cell fabrication.-To generate BP or BP-G electrodes, a slurry was prepared by mixing synthesized BP or BP-G powders (80 wt\%) with a polyvinylidene fluoride (PVDF) binder (10 wt \%, Kureha 7208, Kureha America) pre-dissolved in NMP and Super P (10 wt \%) using a SpeedMixer (FlackTek Inc.). For the $\mathrm{BP} / \mathrm{G}$ mixture electrode, $\mathrm{BP}$ and graphite were mixed at $3000 \mathrm{rpm}$ for $30 \mathrm{~min}$. using a SpeedMixer, after which the mixture (total $80 \mathrm{wt} \%$ ) was mixed with PVDF binder (10 wt $\%)$ and Super P (10 wt $\%)$ for another $30 \mathrm{~min}$. The viscosity of the final slurry was adjusted by the addition of small aliquots of NMP with $30 \mathrm{~s}$ of mixing at $3000 \mathrm{rpm}$ after each addition. The resulting slurry was cast onto a $9 \mu \mathrm{m}$-thick copper foil at a constant speed using either a 3 or 9 mil doctor-blade film coater. All electrodes were dried for $4 \mathrm{~h}$ in a vacuum oven at $110^{\circ} \mathrm{C}$ and dried further overnight in vacuum conditions. Active material loading was $3.5-4.0 \mathrm{mg} / \mathrm{cm}^{2}$ based on the total weight of BP and graphite. The effect of active material loading on electrochemical performances of BP-based anodes was also explored, by fabricating electrodes with lower $\left(1.0-1.9 \mathrm{mg} / \mathrm{cm}^{2}\right)$ and higher $\left(4.5-5.0 \mathrm{mg} / \mathrm{cm}^{2}\right)$ active material loadings.

For 2032-type coin cells, a working electrode was assembled in a half-cell configuration with a Li foil counter/reference electrode
(0.75 mm thick, 99.9\%, Alfa Aesar) and a separator (Celgard 2320) that had been soaked in an electrolyte solution of $1.0 \mathrm{M}$ lithium hexafluorophosphate $\left(\mathrm{LiPF}_{6}\right.$; battery grade, $<50 \mathrm{ppm} \mathrm{HF},<15 \mathrm{ppm} \mathrm{H}_{2} \mathrm{O}$, Sigma Aldrich) dissolved in a 1:1 (v/v) mixture of ethylene carbonate (EC) and dimethyl carbonate (DMC). For FEC-containing electrolyte, $5 \mathrm{wt} \%$ of fluoroethylene carbonate (FEC; 99\%, Sigma-Aldrich) was added to the base electrolyte $\left(1 \mathrm{M} \mathrm{LiPF}_{6}\right.$ in EC:DMC $\left.(1: 1, \mathrm{v} / \mathrm{v})\right)$. All electrolyte preparations and cell assembly operations were carried out in an argon-filled glove box (M. Braun) at moisture and oxygen levels below $0.1 \mathrm{ppm}$.

Electrochemical tests.-BP-G/Li half-cells were used for electrochemical experiments, including cycling and electrochemical impedance spectroscopy (EIS) measurements using a Maccor cycler and a Biologic potentiostat, respectively. The half-cells were discharged (lithiation) and charged (de-lithiation) between 0.01 and $2.0 \mathrm{~V}$ at constant current $(200 \mathrm{~mA} / \mathrm{g}$, which corresponds to approximately $\mathrm{C} / 10$ rate for $\mathrm{BP}_{0.9} \mathrm{G}_{1}$ and $\mathrm{C} / 7$ rate for $\mathrm{BP}_{0.3} \mathrm{G}_{1}$, based on the mixing rule of theoretical capacities of graphite and $\mathrm{BP}$ ) unless otherwise noted; this current was chosen based on the total weight of BP and graphite. For comparison, the specific capacities of BP-G composites were calculated based on either the weight of the BP alone or of the total weight of BP and graphite. For EIS measurements, cell potential was held at $1.0 \mathrm{~V}$ for $2 \mathrm{~h}$, and cell impedance was measured by applying a $5 \mathrm{mV}$ amplitude perturbation over a frequency range of $250 \mathrm{kHz}$ to $25 \mathrm{mHz}$.

Materials characterization.-The particle morphologies of graphite, BP, and BP-G were examined with a scanning electron microscope (SEM, Philips XL30 FEG) at an accelerating voltage of $20 \mathrm{kV}$. Elemental analyses were performed using energy-dispersive X-ray spectroscopy on the Philips XL30 FEG. X-ray diffraction (XRD) patterns of synthesized BP, BP/G, and BP-G samples were obtained using a Rigaku rotating anode instrument with a $\mathrm{Cu} K \alpha$ radiation source $(\lambda=1.541 \AA)$. XRD samples were prepared by grinding synthesized powders and then pressing the powders onto a glass substrate, and XRD patterns were collected over the $2 \theta$ range from $10^{\circ}$ to $80^{\circ}$ using a scan speed of 0.8 degrees per min and a step increment of $0.02^{\circ}$. The electronic conductivities of BP/G mixtures and BP-G composites were investigated using a four-point probe method, wherein BP/G mixture and BP-G composite electrodes (approximately $18 \times 8 \mathrm{~cm}^{2}$ ) were cast onto a glass plate and dried at $110^{\circ} \mathrm{C}$ for $4 \mathrm{~h}$ in a vacuum oven. Measurements were conducted 5 times at different points for accuracy. The effect of wet ballmilling on particle size reduction was assessed by conducting a particle size distribution analysis with a Saturn Digitizer 2 (Micromeritics) using a light scattering analysis technique. Due to the hydrophobic nature of BP, BP was dispersed in NMP before being added to the water in the system. All samples were carefully prepared in an Ar-filled glove box to minimize exposure to air.

\section{Results and Discussion}

Synthesis of BP-G composites.-Figure 1 shows the particle morphologies of pristine graphite, synthesized BP (6h-HEMM), and synthesized BP-G (6h-HEMM). The graphite used in this study displayed a relatively large particle size $\left(\mathrm{d}_{90}=32 \mu \mathrm{m}\right)$ and small surface area $\left(\leq 7.5 \mathrm{~m}^{2} / \mathrm{g}\right)$, and a potato-type shape with a high degree of preferential orientation. As demonstrated in our earlier work and other previous studies, RP can be transformed into BP by HEMM, and maximum BP crystallinity can be achieved under $6 \mathrm{~h}$ of HEMM process. ${ }^{1,16,17,21}$ As shown in Figure 1b, large RP particle sizes with sharp edges changed to a wide range of BP particle sizes $(75 \mathrm{~nm}$ to $71 \mu \mathrm{m}$, $\mathrm{d}_{50}=5.7 \mu \mathrm{m}$ ) with irregular shapes after the HEMM process. The ball-milled, fine BP particles adhered to one another, resulting in agglomerated secondary particles. The BET surface area of synthesized $\mathrm{BP}$ was measured at $7.156 \mathrm{~m}^{2} / \mathrm{g}$, close to the surface area of graphite used in this study. In subsequent HEMM process, the mixture of BP and graphite were subjected to repeated, highly energetic impacts to produce mechanochemically bonded BP-G composites (Fig. 1c). The 


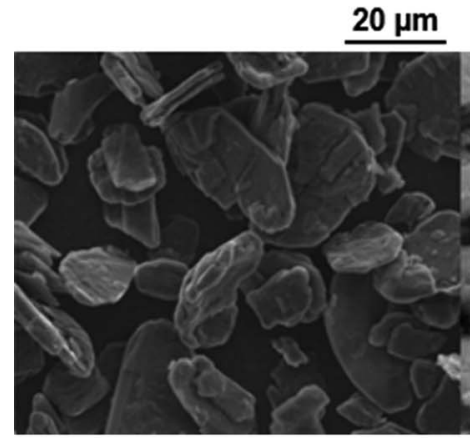

(a)
$5 \mu \mathrm{m}$

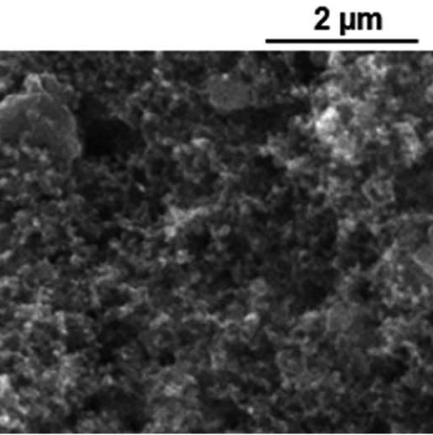

(c)

Figure 1. SEM images of (a) raw graphite, (b) synthesized BP, and (c) synthesized BP-G composite.

HEMM process induces disordered, nano-porous carbons and/or submicron agglomerates with large surface areas, which have a strong tendency to mechanochemically bond to BP particles. ${ }^{22-26}$

Effects of material composition on cyclability.-We attempted to delineate the underlying causes of the wide variability in electrochemical performance of P-C composites in the literature, $1,8,11-13,15-17,19,20$ by carefully examining different factors. First, the effect of BP-G composition on BP-G cyclability was evaluated. The majority of prior research used a weight ratio of 70:30 (BP:carbon), ${ }^{1,11,12,16,17,19}$ with only a few studies using a lower ratio (50:50 wt\% or less) for the synthesis of P-C composites. ${ }^{8,13,15}$ Based on these parameters, we selected two representative $\mathrm{BP}-\mathrm{G}$ compositions $\left(\mathrm{BP}_{0.3} \mathrm{G}_{1}\right.$ vs. $\left.\mathrm{BP}_{0.9} \mathrm{G}_{1}\right)$ to clarify the impact of BP-G composition on BP-G electrochemical behavior.

Three distinct differences in electrochemical performance between $\mathrm{BP}_{0.3} \mathrm{G}_{1}$ and $\mathrm{BP}_{0.9} \mathrm{G}_{1}$ were observed (Fig. 2). First, a more rapid capacity fade was evident over 50 cycles for $\mathrm{BP}_{0.9} \mathrm{G}_{1}$ compared to $\mathrm{BP}_{0.3} \mathrm{G}_{1}$. The remaining capacity of $\mathrm{BP}_{0.9} \mathrm{G}_{1}$ after 50 cycles was $206 \mathrm{mAh} / \mathrm{g}(\mathrm{BP}$ weight-based), significantly lower than that of $\mathrm{BP}_{0.3} \mathrm{G}_{1}(1290 \mathrm{mAh} / \mathrm{g})$. This result suggests that BP-G composition significantly affects the cycle stability of BP-G composites. Our previous study demonstrated that the dramatic capacity fade of $\mathrm{BP}_{0.9} \mathrm{G}_{1}$ was mainly attributed to contact loss resulting from particle cracking or pulverization during the volume change. ${ }^{21}$ This mechanical failure of $\mathrm{BP}_{0.9} \mathrm{G}_{1}$ also caused further electrolyte decomposition, leading to the formation of a thick SEI layer. In contrast, $\mathrm{BP}_{0.3} \mathrm{G}_{1}$ did not show observable cracking or pulverization, suggesting that its structural integrity was well maintained over the 50 cycles. ${ }^{21}$ The increased structural stability of $\mathrm{BP}_{0.3} \mathrm{G}_{1}$ is likely due to both the higher amount of ball-milled graphite, which forms a thick carbon buffering matrix in the electrode, and the for- mation of robust $\mathrm{P}-\mathrm{C}$ bonds unique to this ratio $\mathrm{BP}_{0.3} \mathrm{G}_{1}$. Different from $\mathrm{Si} / \mathrm{C}$ or $\mathrm{SiO}_{\mathrm{x}} / \mathrm{C}$ materials, the $\mathrm{BP}-\mathrm{G}$ composite structure and $\mathrm{P}-\mathrm{C}$ bonds are strongly affected by the phosphorus/carbon composition. ${ }^{8,21}$ According to a previous DFT calculation, ${ }^{27}$ a preferred type of P-C crystal structure is phosphorus-doped graphite when the phosphorus content is low. This structure retains strong $\mathrm{C}-\mathrm{C}$ bonds in a graphene layer-like structure and does not require significant breakup of P-P bonds to generate $\mathrm{P}-\mathrm{C}$ composites, forming robust $\mathrm{P}-\mathrm{C}$ bonds between a phosphorene-like structure and a graphene layer-like structure. ${ }^{8}$ In contrast, complete rearrangement of $\mathrm{P}$ and $\mathrm{C}$ atoms must take place to form a preferred crystal structure for $\mathrm{BP}_{0.9} \mathrm{G}_{1}$, requiring significant breakup of strong P-P bonds or the formation of weak P-P bonds to form P-C bonds. ${ }^{27}$ However, the significant breakup of strong P-P bonds requires more demanding synthesis conditions than HEMM. Therefore, HEMM synthesis might not cause the formation of a stable $\mathrm{BP}_{0.9} \mathrm{G}_{1}$ structure with robust $\mathrm{P}-\mathrm{C}$ bonds.

Second, the discharge-charge profiles of $\mathrm{BP}_{0.9} \mathrm{G}_{1}$ and $\mathrm{BP}_{0.3} \mathrm{G}_{1}$ were found to have markedly different characteristics, as shown in Figs. $2 b$ and $2 \mathrm{c}$. The discharge curve of $\mathrm{BP}_{0.9} \mathrm{G}_{1}$ was steeply sloped below approximately $0.6 \mathrm{~V}\left(\mathrm{vs} . \mathrm{Li}^{+} / \mathrm{Li}\right)$, with a relatively long plateau around $0.7 \mathrm{~V}$ (vs. $\mathrm{Li}^{+} / \mathrm{Li}$ ), and the first discharge capacity of $\mathrm{BP}_{0.9} \mathrm{G}_{1}$ was approximately $1870 \mathrm{mAh} / \mathrm{g}$ (BP weight-based). In contrast, the discharge curve of $\mathrm{BP}_{0.3} \mathrm{G}_{1}$ displayed a gradual incline and short plateau at the same voltages, with an approximate first discharge capacity of $2100 \mathrm{mAh} / \mathrm{g}$. More importantly, the charge curve of $\mathrm{BP}_{0.9} \mathrm{G}_{1}$ showed one plateau near $1.1 \mathrm{~V}$, while that of $\mathrm{BP}_{0.3} \mathrm{G}_{1}$ displayed two plateaus at approximately 1.0 and $1.2 \mathrm{~V}$. These results indicate that $\mathrm{BP}_{0.9} \mathrm{G}_{1}$ might involve a different type of lithiation/delithiation process or electrochemical reaction than $\mathrm{BP}_{0.3} \mathrm{G}_{1}$. Since $\mathrm{P}$ is transformed into $\mathrm{LiP}$ and $\mathrm{Li}_{2} \mathrm{P}$ phases at approximately $0.78 \mathrm{~V}$ and $0.63 \mathrm{~V}$ (vs. $\mathrm{Li}^{+} / \mathrm{Li}$ ),
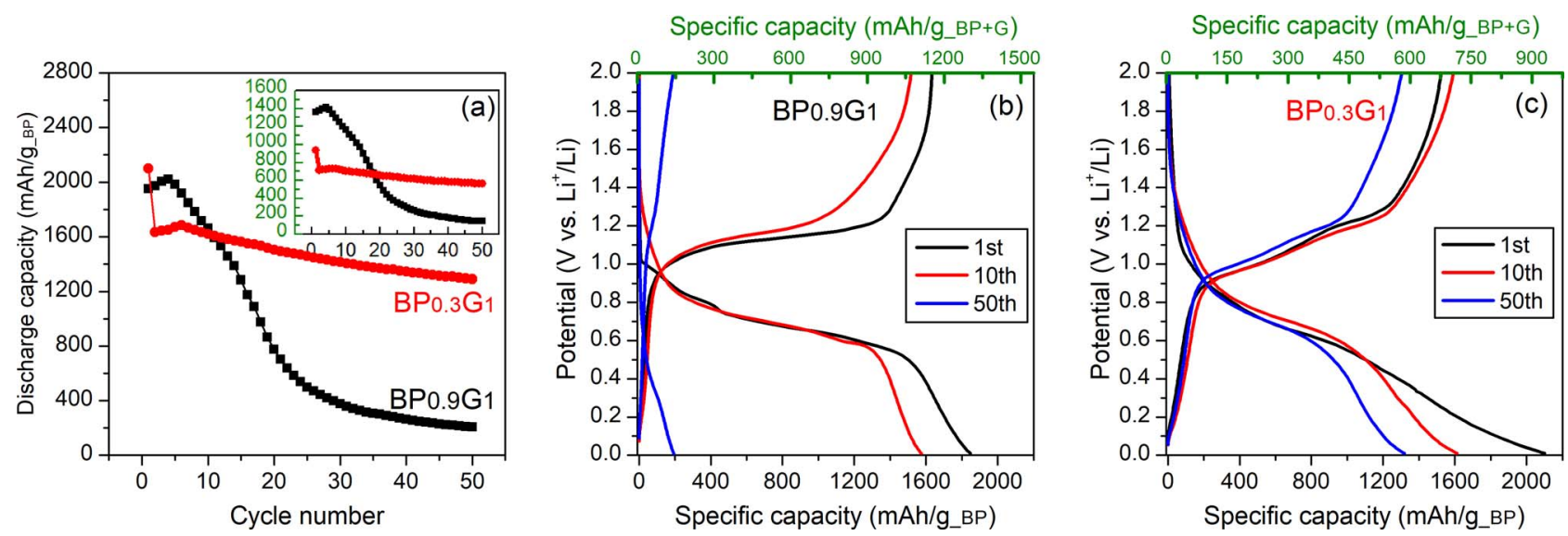

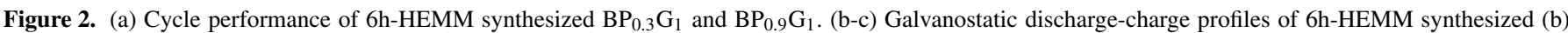

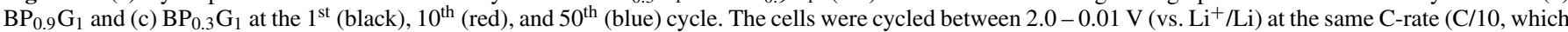

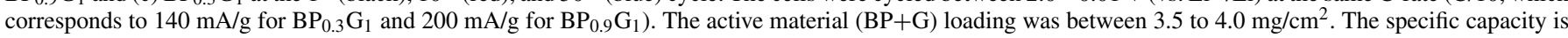
displayed either based on the weight of $\mathrm{BP}$ (black axis) or the weight of $\mathrm{BP}+\mathrm{G}$ (green axis) for comparison. 
respectively, the steep discharge slope below $0.6 \mathrm{~V}$ observed for $\mathrm{BP}_{0.9} \mathrm{G}_{1}$ could be associated with the mechanical degradation of BP$\mathrm{G}$ composites induced by the volume change. ${ }^{1}$ Conversely, the gradual slope profile observed in $\mathrm{BP}_{0.3} \mathrm{G}_{1}$ suggests that $\mathrm{BP}_{0.3} \mathrm{G}_{1}$ either withstands the volume change or experiences fewer volume changeinduced transformations during lithiation. The improved cycle stability of $\mathrm{BP}_{0.3} \mathrm{G}_{1}$ could be due to the different lithiation/delithiation mechanisms.

Third, the first cycle coulombic efficiency of $\mathrm{BP}_{0.3} \mathrm{G}_{1}$ was lower $(73 \%)$ than that of $\mathrm{BP}_{0.9} \mathrm{G}_{1}(88 \%)$. Since $\mathrm{BP}_{0.3} \mathrm{G}_{1}$, with its greater proportion of ball-milled carbon, has a larger surface area than $\mathrm{BP}_{0.9} \mathrm{G}_{1}$, more side reactions, including the formation of the SEI layer, can occur, thereby resulting in a greater loss of irreversible capacity in the first cycle. However, other factors can contribute to the low first cycle coulombic efficiency of $\mathrm{BP}_{0.3} \mathrm{G}_{1}$, which will be discussed subsequently (please see Effects of ballmilling time on cyclability).

Overall, these results strongly suggest that BP-G composition is the dominant factor affecting cycle performance, reversible capacity, and first cycle coulombic efficiency of BP-G composites.

Effects of electrolyte additive on cyclability.-To quantitively evaluate how much BP-G electrochemical performance could be improved by electrolyte additive, both $\mathrm{BP}_{0.3} \mathrm{G}_{1}$ and $\mathrm{BP}_{0.9} \mathrm{G}_{1}$ electrodes were cycled with and without FEC additive. FEC is a well-known electrolyte additive that contributes to the formation of a robust FECderived SEI layer that is much thinner and denser than an EC-derived SEI layer, helping this layer to withstand the stress caused by large volume expansion/contraction upon lithiation/delithiation. ${ }^{28}$

Figure $3 \mathrm{a}$ shows the cycle performance of $\mathrm{BP}_{0.9} \mathrm{G}_{1}$ electrodes with and without FEC additive. The use of FEC additive did not improve the dramatic capacity fade of $\mathrm{BP}_{0.9} \mathrm{G}_{1}$, indicating that the formation of a robust and flexible FEC-derived SEI layer did not mitigate its mechanical degradation. This further confirms that mechanical failure, rather than SEI, was the predominant degradation mechanism implicated in the capacity fade of $\mathrm{BP}_{0.9} \mathrm{G}_{1}$, consistent with our earlier work. ${ }^{21}$ For $\mathrm{BP}_{0.9} \mathrm{G}_{1}$, only the initial reversible capacity increased with the use of FEC additive. This could be because the FEC-derived SEI layer permits faster Li-ion transport at the electrode/electrolyte interface, thereby enhancing the utilization of BP-G active materials within a given amount of time. ${ }^{28}$

For $\mathrm{BP}_{0.3} \mathrm{G}_{1}$ (Fig. $3 \mathrm{~b}$ ), capacity retention was notably improved with FEC additive. The specific capacity (delithiation) of the FECcontaining cell reached $1357 \mathrm{mAh} / \mathrm{g}$ (BP weight-based) at the $13^{\text {th }}$ cycle and had retained $1213 \mathrm{mAh} / \mathrm{g}$ upon the $50^{\text {th }}$ cycle, showing an approximate $90 \%$ capacity retention. In contrast, the FEC-free cell achieved a maximum capacity of $1222 \mathrm{mAh} / \mathrm{g}$ at the $6^{\text {th }}$ cycle, but the capacity dropped to $853 \mathrm{mAh} / \mathrm{g}$ at the end of cycling, showing an approximate $70 \%$ capacity retention. The slight increase in reversible capacity during the initial cycles could be due to a slower electrolyte wetting rate caused by thicker BP-G electrodes with high active material loadings and the significant amount of hydrophobic carbons present in $\mathrm{BP}_{0.3} \mathrm{G}_{1} \cdot{ }^{28}$

The improvement in capacity retention of the FEC-containing cell suggests that the capacity fade of $\mathrm{BP}_{0.3} \mathrm{G}_{1}$ mainly occurred at the electrode/electrolyte interface, with the dominant degradation mechanism being SEI growth caused by further electrolyte decomposition, rather than electrical contact loss caused by severe particle cracking or pulverization. If cracking or pulverization of particles was pronounced in $\mathrm{BP}_{0.3} \mathrm{G}_{1}$, FEC should not have affected cycle performance, as it did for $\mathrm{BP}_{0.9} \mathrm{G}_{1}$. Nevertheless, minor cracks present in some large $\mathrm{BP}_{0.3} \mathrm{G}_{1}$ particles may also contribute to further electrolyte decomposition and the subsequent formation of a thick SEI layer.

The improvement in capacity retention can thus be attributed to the characteristics of the FEC-derived SEI layer, which has excellent mechanical stability that allows it to withstand considerable stress during the lithiation/delithiation process and possesses superior passivation that mitigates further side reactions between anode and electrolyte. ${ }^{28}$ To investigate how the FEC additive improved the capacity retention of $\mathrm{BP}_{0.3} \mathrm{G}_{1}$, the EIS spectra of FEC-free and FEC-containing cells were
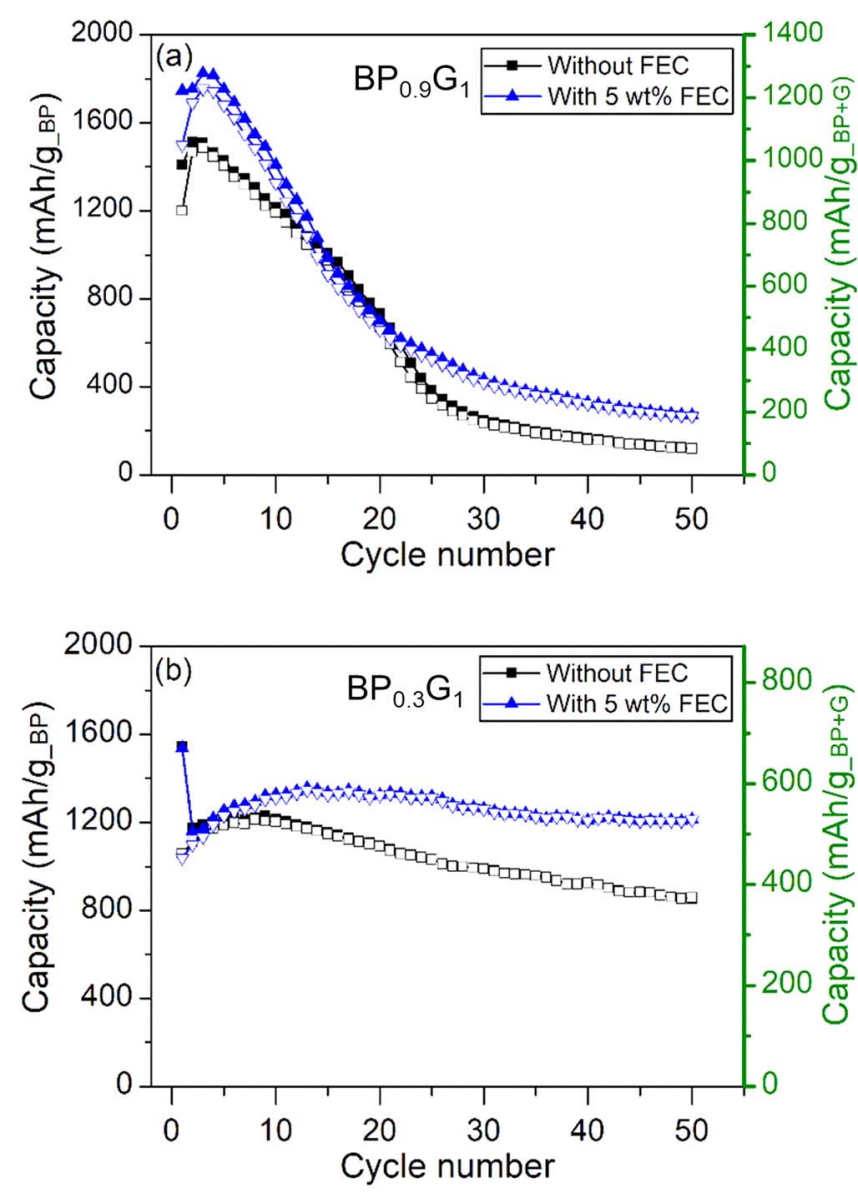

Figure 3. Cycle performance of 6h-HEMM BP-G composites with (blue) and without (black) FEC additive. (a) $\mathrm{BP}_{0.9} \mathrm{G}_{1}$ and (b) $\mathrm{BP}_{0.3} \mathrm{G}_{1}$ were cycled between $2.0-0.01 \mathrm{~V}\left(\mathrm{vs} . \mathrm{Li}^{+} / \mathrm{Li}\right)$ at the same $\mathrm{C}$-rate $(\mathrm{C} / 7$, which corresponds to $200 \mathrm{~mA} / \mathrm{g}$ for $\mathrm{BP}_{0.3} \mathrm{G}_{1}$ and $270 \mathrm{~mA} / \mathrm{g}$ for $\mathrm{BP}_{0.9} \mathrm{G}_{1}$ ). The active material (BP $+\mathrm{G}$ ) loading was between 3.5 to $4.0 \mathrm{mg} / \mathrm{cm}^{2}$. Open and closed symbols represent charge (delithiation) and discharge (lithiation) capacities, respectively. The specific capacity is displayed based on either BP weight (left axis, black) or $\mathrm{BP}+\mathrm{G}$ weight (right axis, green).

evaluated after the $50^{\text {th }}$ cycle. As shown in Figure $4 \mathrm{a}$, the impedance spectra display depressed semicircles in the high-medium frequency range, representative of SEI layer resistance $\left(\mathrm{R}_{\mathrm{SEI}}\right)$ and charge transfer resistance $\left(\mathrm{R}_{\mathrm{ct}}\right)$, and an inclined line in the low-frequency range assigned to solid-state diffusion inside particles. Distinct differences between FEC-containing and FEC-free cells were observed in the depressed semicircles. Based on the equivalent circuit model (Fig. 4b) used to fit the EIS data, the $\mathrm{R}_{\mathrm{SEI}}$ and $\mathrm{R}_{\mathrm{ct}}$ of the FEC-containing cell were lower than those of the FEC-free cell after 50 cycles. This indicates that the thick SEI layer formation and sluggish charge transfer reaction occurring in $\mathrm{BP}_{0.3} \mathrm{G}_{1}$ was alleviated by the use of FEC additive. In an FEC-free cell, thick SEI layers formed due to severe electrolyte decomposition resulting from unstable SEI layers and minor cracks in particles. In contrast, the FEC-containing cell maintained stable SEI layers, suppressing SEI growth and improving interfacial kinetics. Although the FEC-free cell exhibited higher interfacial resistances $\left(\mathrm{R}_{\mathrm{SEI}}\right.$ and $\left.\mathrm{R}_{\mathrm{ct}}\right)$ than the FEC-containing cell, it still showed well-defined semicircles in the high-mid frequency range and a similar slope for the inclined line in the low-frequency range to those of FECcontaining cells. This indicates that $\mathrm{BP}_{0.3} \mathrm{G}_{1}$ has no severe structural disruptions or electrical contact loss, maintaining charge transfer and solid-state ion diffusion processes. This further proves that the capacity degradation of $\mathrm{BP}_{0.3} \mathrm{G}_{1}$ is governed by the interfacial phenomena rather than by the electrical contact loss caused by particle cracking or pulverization. 

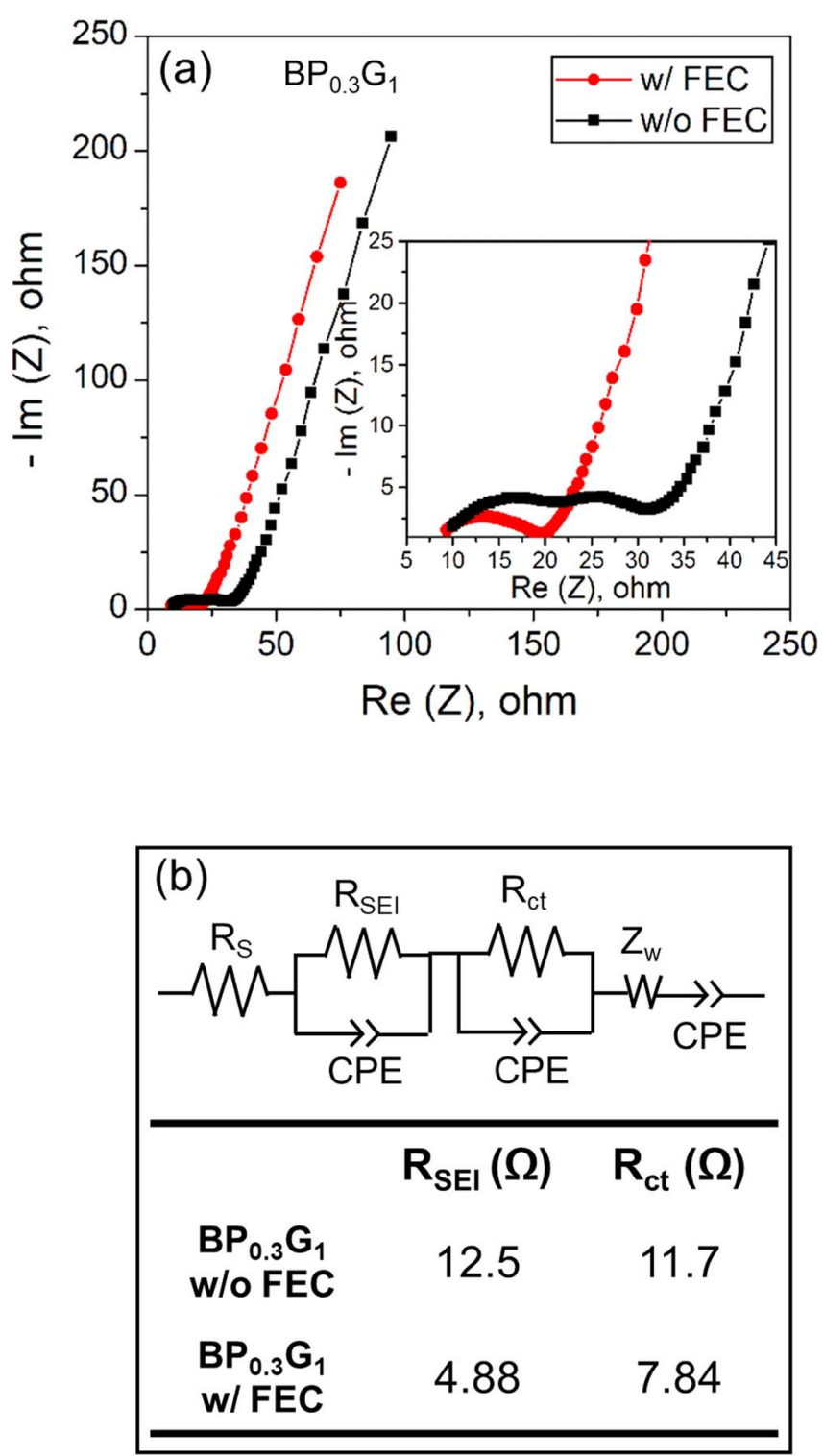

Figure 4. (a) EIS spectra of $\mathrm{BP}_{0.3} \mathrm{G}_{1}$ electrodes after 50 cycles with (red) and without (black) FEC additive. (b) Equivalent circuit model used to fit the EIS spectra and the resulting interfacial resistance values.

Notably, the use of FEC additive had no influence on first cycle coulombic efficiency and initial reversible capacity of $\mathrm{BP}_{0.3} \mathrm{G}_{1}$, as shown in Figure 3b. The first cycle coulombic efficiency (69\%) and initial reversible capacity $\left(1058 \mathrm{mAh} / \mathrm{g}_{\_}\right.$вP $)$of FEC-free cells were similar to those $\left(68 \%\right.$ and $1039 \mathrm{mAh} / \mathrm{g}_{\text {BBP }}$ ) of FEC-containing cells.

Further investigation on the electrochemical performance of $\mathrm{BP}_{0.3} \mathrm{G}_{1}$ was conducted by varying the HEMM synthesis conditions to explore ways of improving first cycle coulombic efficiency and initial reversible capacity while maintaining good cyclability.

Effects of ballmilling time on cyclability.-Ballmilling time is considered the most important parameter for synthesizing composite materials with HEMM. ${ }^{29,30}$ Previous studies have used different ballmilling times, which might explain the significant differences in P-C electrochemical performances among them. , $^{1,12,16,17}$ Several processing variables affect HEMM process: type of mill, material of milling media, ball-to-powder ratio (BPR), milling atmosphere, milling time, milling speed, and size of milling media, and the ballmilling time used in one study is thus not directly comparable with that used in another study. ${ }^{1,8,12,16,17}$ Ballmilling times, along with
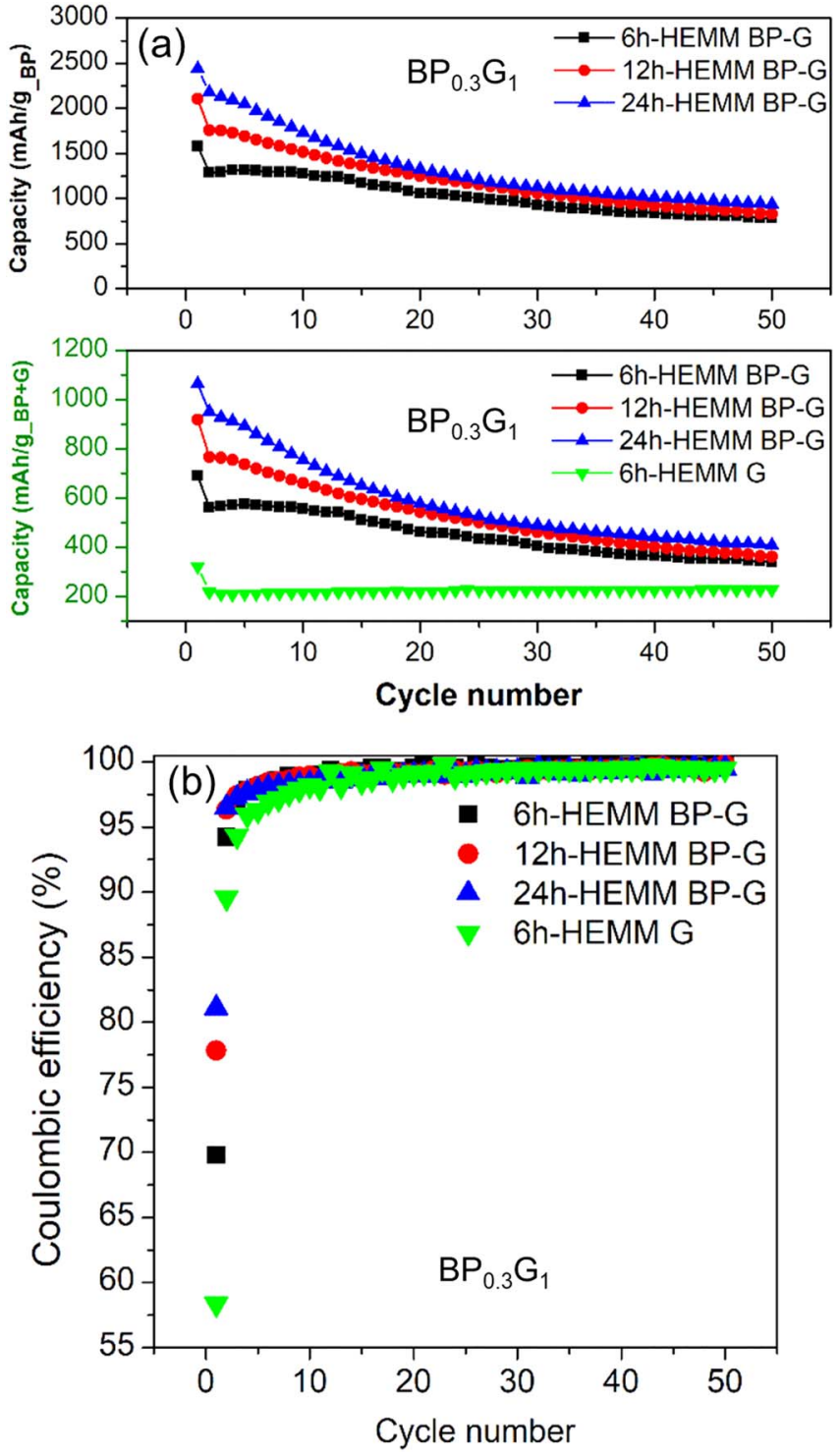

Figure 5. (a) Cycle performance and (b) coulombic efficiency of $\mathrm{BP}_{0.3} \mathrm{G}_{1}$ composites synthesized with different HEMM synthesis times: 6h-HEMM (black square), 12h-HEMM (red circle), and 24h-HEMM (blue triangle). For comparison, 6h-HEMM synthesized graphite was included in the plot (green down-triangle). Cells were cycled without FEC additive between $2.0-0.01 \mathrm{~V}$ (vs. $\mathrm{Li}^{+} / \mathrm{Li}$ ) with a current density of $200 \mathrm{~mA} / \mathrm{g}$. The active material $(\mathrm{BP}+$ G) loading was between 4.0 to $4.4 \mathrm{mg} / \mathrm{cm}^{2}$. The specific capacity (discharge, lithiation) is displayed based on either BP weight [top subfigure in (a)] or BP $+\mathrm{G}$ weight [bottom subfigure in (a)]

other HEMM synthesis conditions, must be consistent if comparisons are to be made.

We explored the different HEMM-produced BP-G composites and how the ballmilling process therein affected electrochemical performance by synthesizing $\mathrm{BP}_{0.3} \mathrm{G}_{1}$ composites with different ballmilling times and comparing their cyclability, initial reversible capacity, and first cycle coulombic efficiency. No electrolyte additive was used in the cells which might have confounded these assessments.

As shown in Figures 5a and 5b, increases in ballmilling time were associated with improvements to both initial reversible capacity and first cycle coulombic efficiency in $\mathrm{BP}_{0.3} \mathrm{G}_{1}$. The first discharge (lithiation) and charge (delithiation) capacities of $\mathrm{BP}_{0.3} \mathrm{G}_{1}$ composites ball-milled for $6 \mathrm{~h}, 12 \mathrm{~h}$, and $24 \mathrm{~h}$ were 1583/1105, 2104/1638, and $2440 / 1978 \mathrm{mAh} / \mathrm{g}$ (based on the weight of BP), respectively. The corresponding first cycle coulombic efficiencies were $69.8,77.8$, and 


\begin{tabular}{|c|c|c|}
\hline Active material & Composition & Conductivity (S/cm) \\
\hline $\begin{array}{c}\text { BP ball-milled for } \\
6 \mathrm{~h}\end{array}$ & 92.5:7.5 (AM: PvdF) & $\begin{array}{l}\text { N/A (beyond the } \\
\text { measurement range) }\end{array}$ \\
\hline Pristine graphite & 92.5:7.5 (AM: PvdF) & 5.26 \\
\hline $\begin{array}{l}\text { BP/G mixture } \\
(70: 30 \mathrm{wt} \%)\end{array}$ & $\begin{array}{c}\text { 80:10:10 } \\
\text { (AM:CB:PvdF) }\end{array}$ & 1.36 \\
\hline $\begin{array}{r}\mathrm{BP} / \mathrm{G} \text { mixture } \\
(44: 56 \mathrm{wt} \%)\end{array}$ & $\begin{array}{c}\text { 80:10:10 } \\
\text { (AM:CB:PvdF) }\end{array}$ & 4.87 \\
\hline
\end{tabular}

$81.1 \%$, respectively. These data indicate that longer HEMM allowed complete bonding of ball-milled disordered and/or nano-porous carbons to BP particles, thereby improving the activation of BP material. Shorter ballmilling times resulted in a portion of BP particles remaining locally isolated from, or only loosely connected to, ball-milled carbons; these were not involved in the electrochemical reaction due to their low electronic conductivity. These isolated BP particles were also likely to be subject to severe mechanical degradation and the associated contact loss, further lowering the first cycle coulombic efficiency.

The strong connection between ball-milled carbon and BP (BP-G form) that accompanied with increased ballmilling time was evaluated by comparing the electronic conductivities among BP-G composites ball-milled for different lengths of time. For comparison, the electronic conductivities of $\mathrm{BP}$, graphite, and $\mathrm{BP} / \mathrm{G}$ mixture electrodes are listed in Table I. As expected, the synthesized BP exhibited much lower electronic conductivity than graphite. As the graphite content in $\mathrm{BP} / \mathrm{G}$ mixtures increased, the electronic conductivity of $\mathrm{BP} / \mathrm{G}$ mixtures increased due to enhanced inter-particle conductivity via contributions from the graphite particles. However, it should be noted that the inner-particle conductivity of BP particles is not improved by the simple mixing process. The $6 \mathrm{~h}-\mathrm{HEMM}$ synthesized $\mathrm{BP}_{0.3} \mathrm{G}_{1}$, wherein the composition is the same as BP/G (44:56 wt\%) mixture, had much lower conductivity $(0.16 \mathrm{~S} / \mathrm{cm})$ than the corresponding $\mathrm{BP} / \mathrm{G}$ mixture $(4.87 \mathrm{~S} / \mathrm{cm})$, but much higher conductivity than BP. This is because BP are chemically bonded to carbon to generate BP-G composite particles (BP-G form), which improved the inner-particle conductivity although the inter-particle conductivity was lower. The BP-G particles no longer retain the original conductivities of $\mathrm{BP}$ or graphite because of their structural and bond changes. That is, the lowered electronic conductivity upon ballmilling is the consequence of the material change from BP/G mixture to BP-G composite, indicating strong bonds between $\mathrm{BP}$ and carbon.

Note that the electronic conductivity of $\mathrm{BP}_{0.3} \mathrm{G}_{1}$ further decreased as ballmilling time increased (Fig. 6). The reduced electronic conductivity observed with increased ballmilling time suggests the presence of a greater amount of BP-G particles. As the ballmilling process proceeds, more $\mathrm{BP} / \mathrm{G}$ mixture is converted to $\mathrm{BP}-\mathrm{G}$ form due to associated strong mechanochemical effect, thereby resulting in increases in first cycle coulombic efficiency and reversible capacity of $\mathrm{BP}_{0.3} \mathrm{G}_{1}$.

The difference between the $\mathrm{BP} / \mathrm{G}$ mixture and $\mathrm{BP}-\mathrm{G}$ composite forms in the BP-G electrode can be further elucidated with SEM images and EDAX analyses (Fig. 7). With sufficient ballmilling time, the BP-G electrode contained predominantly the BP-G composite from wherein carbon and phosphorus were homogeneously distributed without any clear boundaries between the two elements, indicating that carbon and phosphorus were co-localized and bonded (Fig. 7a). In contrast, the EDAX image of the BP/G mixture form showed that phosphorus was locally concentrated, with distinct boundaries between carbon and phosphorus elements (Fig. 7b). With insufficient ballmilling time, the BP/G mixture form, wherein BP particles are not chemically bonded to ball-milled carbons but simply mixed with graphite, was observable in the BP-G electrode and typically seen near large BP particles $(>5 \mu \mathrm{m})$.

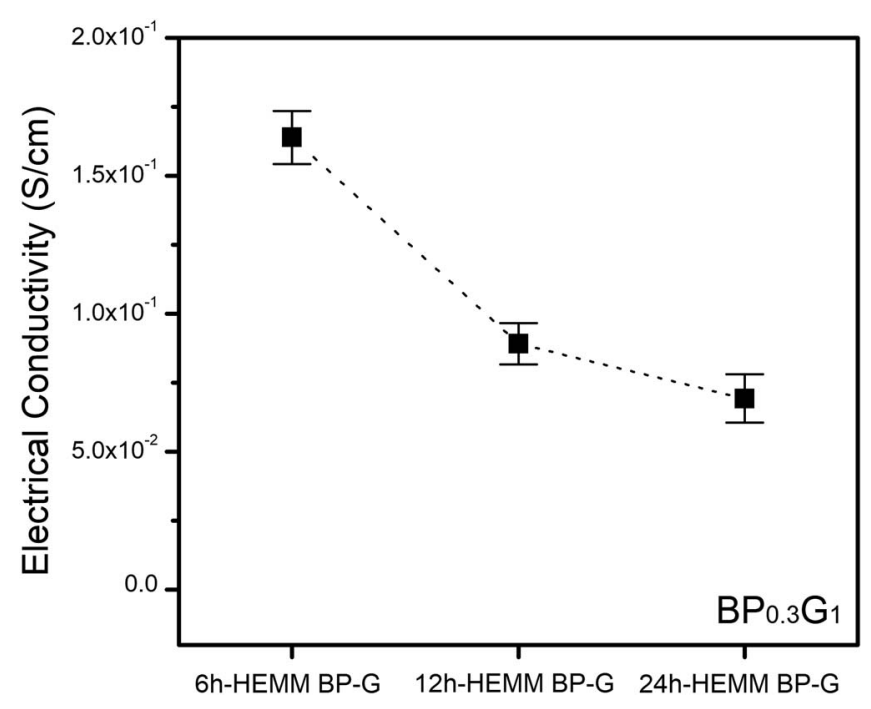

Figure 6. Dependence of electric conductivity of $\mathrm{BP}_{0.3} \mathrm{G}_{1}$ on HEMM synthesis time.

The change from BP/G to BP-G form was also supported by the observed XRD patterns. As shown in Figure 8, the XRD pattern of the $\mathrm{BP} / \mathrm{G}$ mixture shows discrete diffraction peaks related to both BP and graphite. After $6 \mathrm{~h}$ of ballmilling, the two main diffraction peaks ([002] and [004]) corresponding to graphite almost disappeared, and the three main peaks related to BP ([020], [021], and [111], JCPDS 01-073-1358) significantly diminished. After $12 \mathrm{~h}$ of ballmilling, the diffraction peaks associated with BP completely disappeared, leaving only an asymmetrical, broadened peak near $25^{\circ}$. This is not simply due to the particle amorphization induced by the milling process but also the formation of new BP-G composites with amorphous phase and $\mathrm{P}-\mathrm{C}$ bonds. As reported in our previous work, ${ }^{21} \mathrm{BP}$ remains its crystalline phase and related intensities are not reduced during ballmilling, unlike what is observed in graphite. ${ }^{22}$ During ballmilling, the graphite crystalline structure changes to an amorphous turbostatic structure, wherein [002] and [100] peaks are greatly diminished and broadened. ${ }^{22,26}$ If no chemical bonds between phosphorus and carbon were formed in BP-G particles, clear BP-related peaks would have presented in the BP-G samples, similar as the BP/G mixture sample. As suggested by previous studies, some P-P bonds in BP were broken down to form new P-C bonds in the BP-G composite. ${ }^{8,21,31,32}$ The formation of $\mathrm{P}-\mathrm{C}$ bonds in $\mathrm{BP}_{0.3} \mathrm{G}_{1}$ is further supported by the appearance of a new peak near $43^{\circ}$ (marked with diamond symbols) after ballmilling. This new peak could be a unique feature of $\mathrm{BP}_{0.3} \mathrm{G}_{1}$ structure suggesting a new $\mathrm{P}-\mathrm{C}$ bond. Notably, $\mathrm{BP}_{0.9} \mathrm{G}_{1}$ exhibited a different XRD pattern that did not contain the new peak observed in $\mathrm{BP}_{0.3} \mathrm{G}_{1} \cdot{ }^{21}$ This indicates that different types of $\mathrm{P}-\mathrm{C}$ bonds are formed in $\mathrm{BP}-\mathrm{G}$ composites depending on their composition, as suggested by previous theoretical studies. ${ }^{27,31,32}$

Although increases in ballmilling time improved initial reversible capacity and first cycle coulombic efficiency of $\mathrm{BP}_{0.3} \mathrm{G}_{1}$, it did not improve the cycle performance (Fig. 5). The remaining capacity of the $\mathrm{BP}_{0.3} \mathrm{G}_{1}$ ball-milled for $24 \mathrm{~h}$ was only $934 \mathrm{mAh} / \mathrm{g}_{-} \mathrm{BP}$ $\left(407 \mathrm{mAh} / \mathrm{g}_{-} \mathrm{BP}+\mathrm{G}\right)$ at the end of 50 cycles, slightly higher than the other samples. This suggests that improved links between phosphorus and carbon (i.e., a complete transformation of BP/G to BP-G form) can increase initial reversible capacity and first cycle coulombic efficiency of BP-G, but not cycle performance. For comparison, the capacity $(220 \mathrm{mAh} / \mathrm{g})$ of the 6h-HEMM graphite (reference cell) is also shown, demonstrating that BP-G particles did contribute to total cell capacity.

It should be emphasized that synthesized $\mathrm{BP}_{0.3} \mathrm{G}_{1}$ particles showed a wide range of particle sizes, including particles more than 20 $\mu \mathrm{m}$ in diameter (Fig. 9). In addition, no significant differences in 
(a)
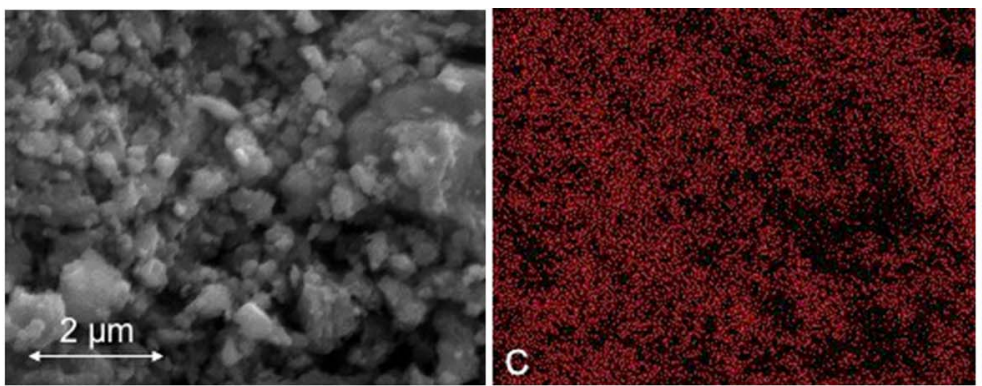

(b)
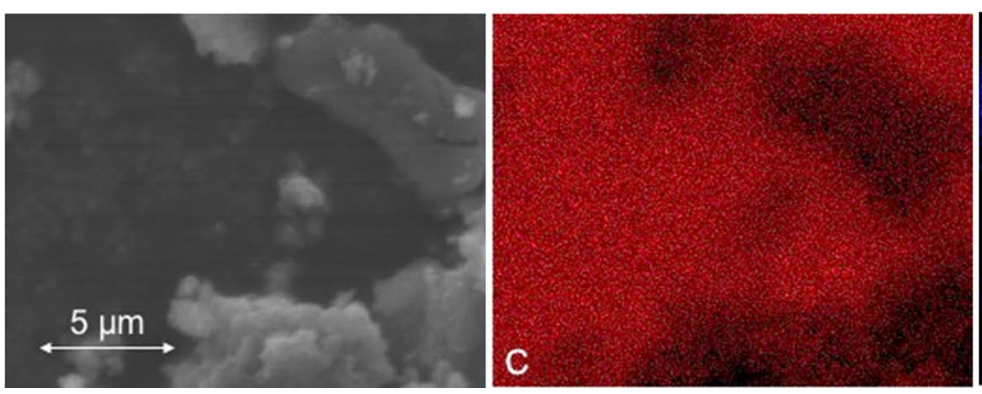
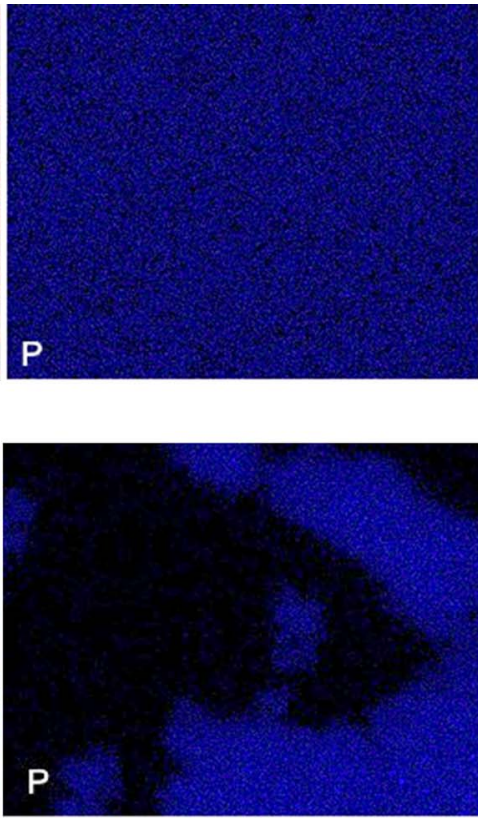

Figure 7. SEM images of BP-G and the corresponding EDAX mapping of carbon (red) and phosphorus (blue): (a) BP-G form and (b) BP/G form co-exist in BP-G composite.

particle sizes were observed between 6h-HEMM and 24h-HEMM $\mathrm{BP}_{0.3} \mathrm{G}_{1}$ when a shaker-type mill was used. This suggests that some large BP-G particles were vulnerable to volume change-induced stress and suffered cracking or pulverization, subsequently resulting in electrolyte decomposition and SEI growth. Thus, reducing the particle size of BP-G materials is essential for further improving cycle performance, as has been reported for other high capacity anode materials.

Effects of modifications to ballmilling process on cyclability.Two different synthetic approaches were employed to reduce the size of BP-G particles while maintaining the strong bonds between phosphorus and carbon. The first approach was to apply an additional wet ballmilling step after BP-G synthesis using a dual asymmet-

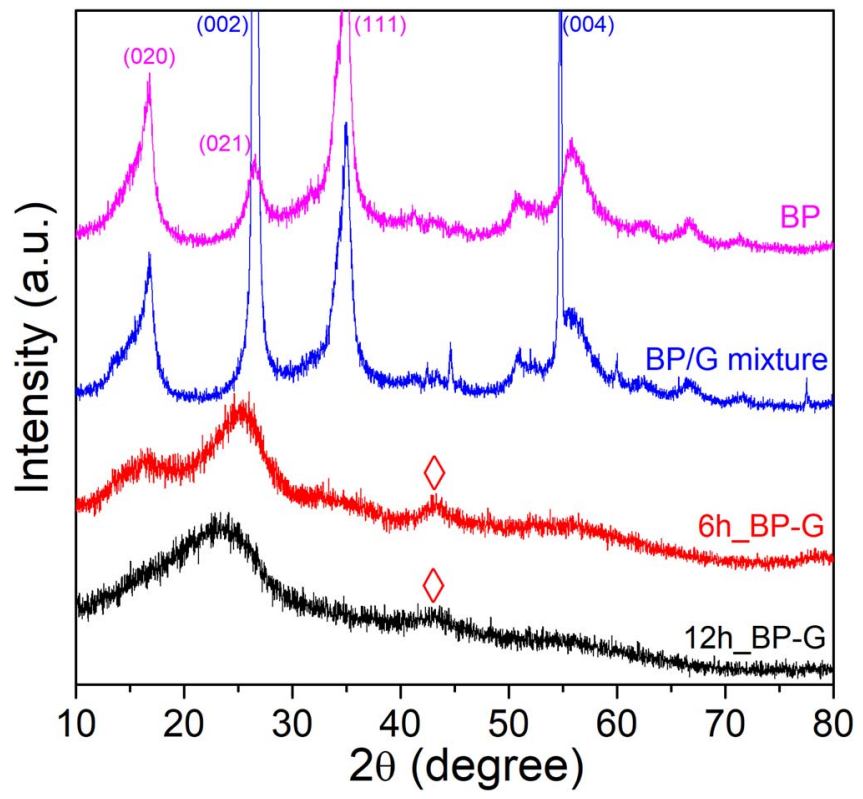

Figure 8. XRD patterns of $\mathrm{BP}, \mathrm{BP} / \mathrm{G}$ mixture, 6h-HEMM $\mathrm{BP}_{0.3} \mathrm{G}_{1}$, and $12 \mathrm{~h}-\mathrm{HEMM} \mathrm{BP} \mathrm{BP}_{0.3} \mathrm{G}_{1}$ ric centrifuge-type mixer to overcome the intrinsic limitations of a shaker/mixer mill. Although a shaker/mixer mill can be beneficial in producing BP materials with greater crystallinity than a planetary-type
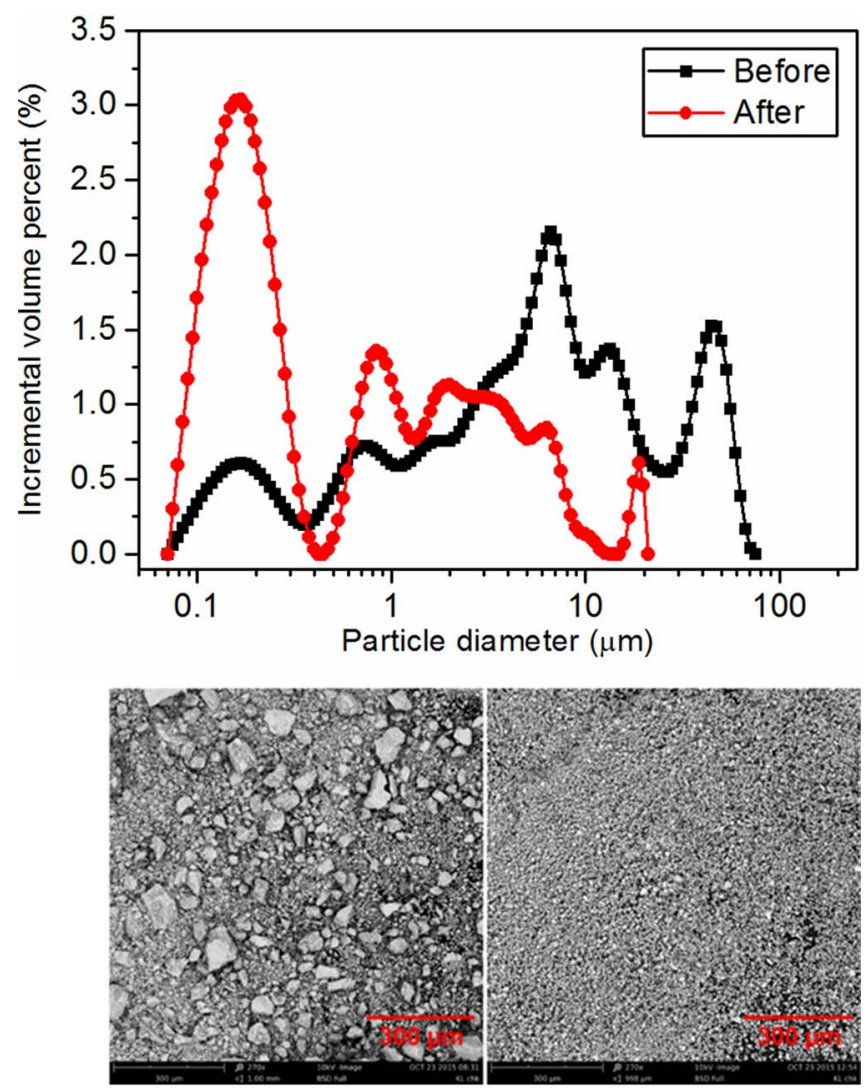

Before

After

Figure 9. Change in particle size distributions after additional wet ballmilling step. 

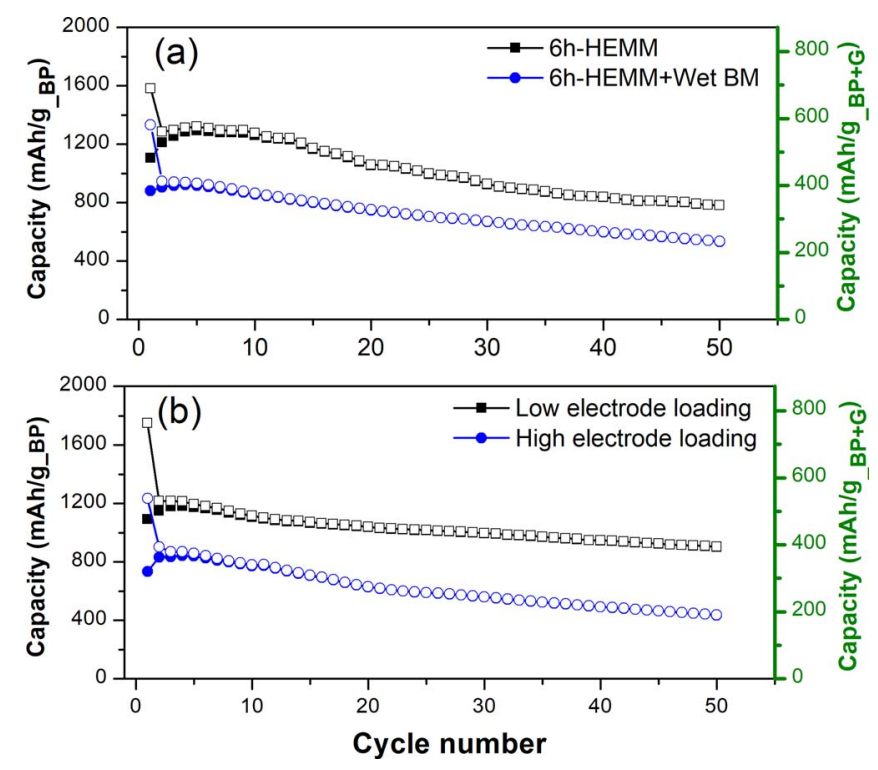

Figure 10. (a) Cycle performance of $6 \mathrm{~h}-\mathrm{HEMM} \mathrm{BP}_{0.3} \mathrm{G}_{1}$ (black square) vs. 6h-HEMM followed by wet ballmilling processed $\mathrm{BP}_{0.3} \mathrm{G}_{1}$ (blue circle); (b) cycle performance of $12 \mathrm{~h}-\mathrm{HEMM} \mathrm{BP}_{0.3} \mathrm{G}_{1}$ with a high $\left(5.0 \mathrm{mg} / \mathrm{cm}^{2}\right.$, blue, circle) and low $\left(1.9 \mathrm{mg} / \mathrm{cm}^{2}\right.$, black, square) active material $(\mathrm{BP}+\mathrm{G})$ loading.

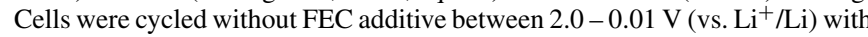
a current density of $200 \mathrm{~mA} / \mathrm{g}$. Open and closed symbols represent discharge (lithiation) and charge (delithiation) capacities, respectively. The specific capacity is displayed based on either BP weight (left axis, black) or BP + G weight (right axis, green).

mill, it does not effectively reduce particle size nor produce homogeneous particles. ${ }^{17}$

As shown in Figure 9, the additional wet ballmilling process increased the homogeneity of BP particle size by reducing the particle size. The mean particle size of $\mathrm{BP}\left(11.8 \mu \mathrm{m}, \mathrm{d}_{50}=5.7 \mu \mathrm{m}\right)$ was significantly reduced to $0.8 \mu \mathrm{m}\left(\mathrm{d}_{50}=2.1 \mu \mathrm{m}\right)$ after the wet ballmilling process. Large BP particles virtually disappeared, and considerable numbers of nano- and submicron-sized particles were generated. Despite the reduction in particle size, however, the cycle performance of $\mathrm{BP}_{0.3} \mathrm{G}_{1}$ improved only slightly, and rather the initial reversible capacity worsened (Fig. 10). The $\mathrm{BP}_{0.3} \mathrm{G}_{1}$ processed by 6 h-HEMM combined with wet ballmilling showed a gradual decrease in reversible capacity $(903 \mathrm{mAh} / \mathrm{g}$, after the first cycle) to $568 \mathrm{mAh} / \mathrm{g}$ at the end of the 50th cycle. This capacity loss (37.1\% drop) was slightly better than that $(39.2 \%)$ observed for $\mathrm{BP}_{0.3} \mathrm{G}_{1}$ synthesized without the additional wet ballmilling. However, the reversible capacity of $\mathrm{BP}_{0.3} \mathrm{G}_{1}$ was reduced, and the first cycle coulombic efficiency dropped slightly (70\% vs. $66 \%$ ). This is probably due to the poor electrolyte impregnation in a dense electrode with a high active material loading. The nano and submicron-sized BP-G particles produced by wet ball milling likely lead to a reduction in porosity and an increase in active material loading of the electrode. This strongly affects electrolyte transport into the pore networks of the electrode active material, with concomitant effects on the electrode wetting rate. ${ }^{28}$ Indeed, it was observed that the active material loading of $\mathrm{BP}_{0.3} \mathrm{G}_{1}$ electrode greatly increased after wet ballmilling to $5.4 \mathrm{mg} / \mathrm{cm}^{2}$ from $3.9 \mathrm{mg} / \mathrm{cm}^{2}$, indicating that the lower reversible capacity of $\mathrm{BP}_{0.3} \mathrm{G}_{1}$ was a consequence of the denser electrode. The greater surface areas of nano- and submicron-sized BP-G particles also contribute to slower electrolyte wetting.

We set out to confirm these speculations by exploring the effect of active material loading on the electrochemical performance of $\mathrm{BP}_{0.3} \mathrm{G}_{1}$ in further depth. $\mathrm{BP}_{0.3} \mathrm{G}_{1}$ electrodes with different active material loadings were prepared with varying thicknesses of electrodes. As shown in Figure 10, active material loading had a significant influence on reversible capacity and cyclability. The electrode with low active material loading $\left(1.9 \mathrm{mg} / \mathrm{cm}^{2}\right)$ showed higher reversible capacity
(1217 $\mathrm{mAh} / \mathrm{g}$ after the first cycle) and significantly better cycle performance (capacity loss of 25\%) than those of the electrode with high active material loading $\left(5.0 \mathrm{mg} / \mathrm{cm}^{2}\right)$. This result confirms that decreases in reversible capacity and capacity retention of $\mathrm{BP}_{0.3} \mathrm{G}_{1}$ after wet ballmilling were mainly caused by increased active material loading in the electrode. Notably, the cycle performance observed for high loading (capacity loss of 52\%) was significantly improved by low active material loading (capacity loss of $25 \%$ ), indicating that active material loading parameters exert a stronger effect on the cyclability of BP-G than other factors such as FEC additive or ballmilling time.

Another possible explanation for the lowered reversible capacity of $\mathrm{BP}_{0.3} \mathrm{G}_{1}$ after additional ball milling is that the wet ballmilling process might not be beneficial in maintaining the strong connections established between phosphorus and carbon. Since wet ballmilling can disperse agglomerated particles in solution, it is generally effective for reducing particle size. Adversely, however, it may loosen or sever the bonds between BP and ball-milled carbon, transforming BP-G back to $\mathrm{BP} / \mathrm{G}$ form. It might also attenuate the strong mechanochemical reactions that occur during HEMM, which is antithetical to maintaining good connections between phosphorus and ball-milled carbon.

To avoid the adverse effects of additional wet ballmilling, the next synthetic approach we used was to incorporate a solvent-free planetary ballmilling (PBM) prior to shaker/mixer milling (HEMM). While a shaker/mixer mill provides efficient impact interactions for mechanochemical reactions due to its "breaking" mode, wherein the impact of balls on the particle is dominated by normal collision forces, a planetary-type mill is effective in reducing particle size during its "peeling" mode caused by dominant shear forces. By combining these two processes (PBM + HEMM), nano- and submicron-sized BP-G particles are produced while preserving the strong connections between phosphorus and carbon.

As shown in Figure 11a, the multi-step ballmilling (PBM + HEMM) approach significantly affected the cycle performances of BP-G composites. BP-G composites synthesized by PBM + HEMM showed excellent reversible capacity $(2,285 \mathrm{mAh} / \mathrm{g}$ after 1 cycle $)$ and superior cycling stability, with a capacity retention of $80 \%$ over 150 cycles $\left(1,827 \mathrm{mAh} / \mathrm{g}\right.$ at the $150^{\text {th }}$ cycle $)$ compared to other BP-G composites (6h-HEMM and 24h-HEMM). This synthesis protocol produced active material loadings similar to one another, preventing active material loading effects on cycle performance. In addition, the first cycle coulombic efficiency ( $82 \%$ ) was significantly higher for the multi-step protocol than for the HEMM-only processes (6h-HEMM BP-G: 65\%, 24h-HEMM BP-G: 75\%). However, these improvements were only observed upon combining PBM with HEMM. No improvements were observed when PBM or HEMM alone was used for BP-G synthesis.

Improvements in BP-G cyclability and reversible capacity by PBM + HEMM process are attributed to the combined effect of reduced particle size and robust connections between phosphorus and carbon. While the PBM step reduced particle size, the HEMM process was essential to facilitating strong connections between phosphorus and carbon due to its dominant impact interaction mode. The multi-step protocol was thereby able to mitigate volume-change induced cracking or pulverization of BP-G particles and subsequent electrolyte decomposition successfully. As demonstrated in the SEM image (Fig. 11d), no obvious particle cracking or pulverization was observed, and the structural integrity of the electrode was well maintained after 150 cycles. The improved cycle performance of the PBM + HEMM sample was further investigated by comparing the EIS spectra of three samples, 6h-HEMM, 24h-HEMM, and PBM + HEMM, as shown in Fig. 11c. The equivalent circuit model described previously (Fig. 4b) was used to fit the EIS spectra. Based on fitting results, $R_{S E I}$ and $R_{c t}$ of the PBM + HEMM sample after 150 cycles were 15 and $61 \Omega$, respectively, lower than those for both 6 h-HEMM $\left(\mathrm{R}_{\mathrm{SEI}}: 48 \Omega\right.$ and $\mathrm{R}_{\mathrm{ct}}: 201 \Omega$ ) and $24 \mathrm{~h}-\mathrm{HEMM}\left(\mathrm{R}_{\mathrm{SEI}}: 20 \Omega, \mathrm{R}_{\mathrm{ct}}: 72 \Omega\right.$ ) samples. This demonstrates that the PBM + HEMM sample did not experience significant electrolyte decomposition followed by SEI growth, while the 6h-HEMM and 24-HEMM samples did. 

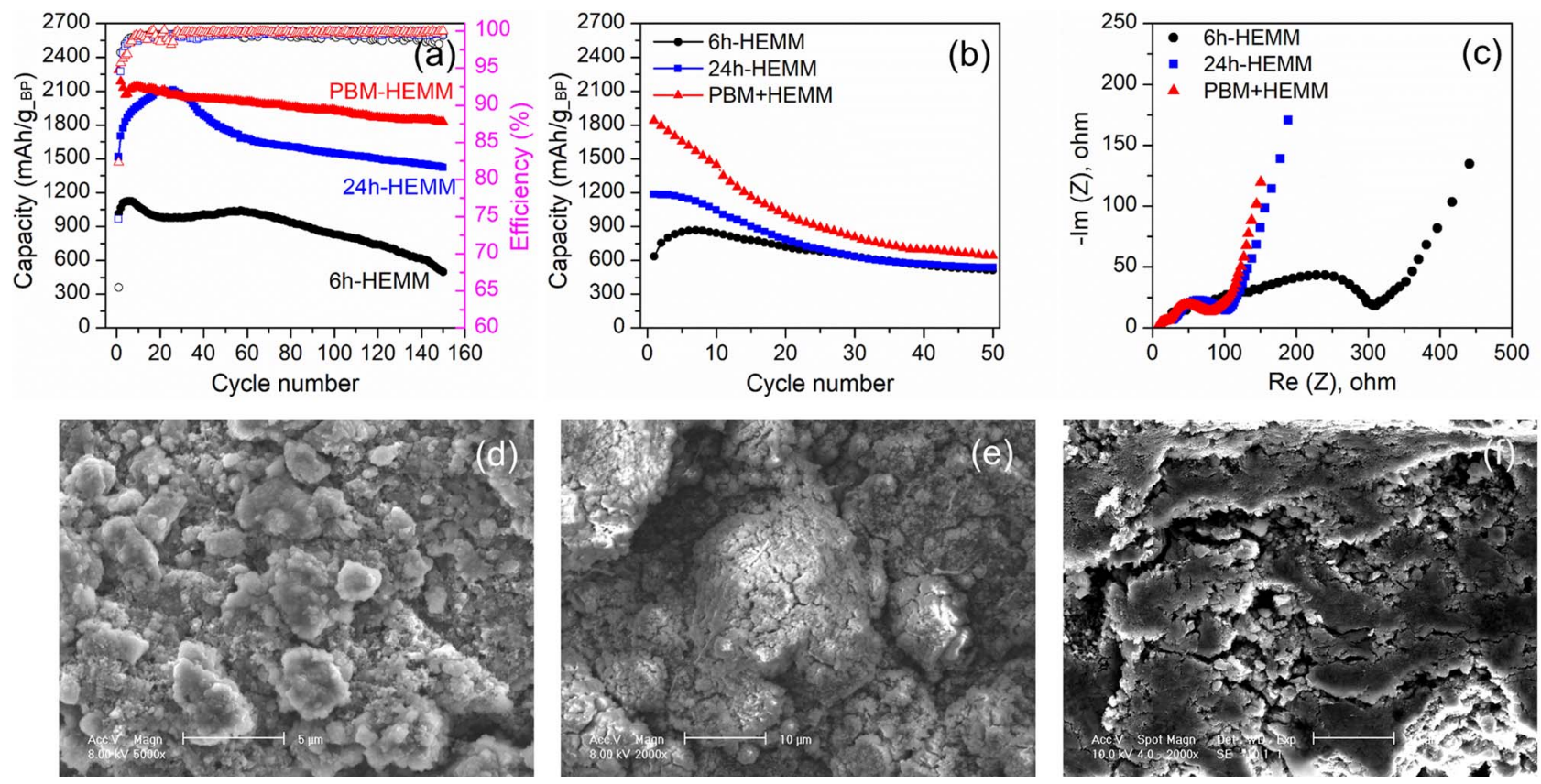

Figure 11. Cycle performance of BP-G (50:50 wt\%) electrodes synthesized with different processes. The cells were cycled with FEC additive between $2.0-0.01 \mathrm{~V}$ (vs. $\mathrm{Li}^{+} / \mathrm{Li}$ ) with a current density of either (a) $100 \mathrm{~mA} / \mathrm{g}$ or (b) $1000 \mathrm{~mA} / \mathrm{g}$. The capacity is charge (delithiation) capacity, which is based on the weight of BP. Open symbol corresponding to coulombic efficiency is displayed in the right axis. The active material (BP $+\mathrm{G})$ loading was between 1.1 to $1.5 \mathrm{mg} / \mathrm{cm}^{2}$. (c) EIS spectra of 6h-HEMM, 24h-HEMM and PBM + HEMM processed BP-G (50:50 wt\%) electrodes after 150th cycles. Top-view SEM images of PBM + HEMM processed BP-Gs are shown after the $150^{\text {th }}$ cycle at (d) $100 \mathrm{~mA} / \mathrm{g}$ and (e) $1000 \mathrm{~mA} / \mathrm{g}$, respectively. (f) Cross-sectional SEM image of PBM + HEMM processed BP-G after the $150^{\text {th }}$ cycle at $1000 \mathrm{~mA} / \mathrm{g}$.

However, the PBM + HEMM sample was not robust enough to withstand high C-rates. As shown in Figure 11b, the sample exhibited a rapid capacity fade at a high current density of $1000 \mathrm{~mA} / \mathrm{g}$ (roughly close to $1 \mathrm{C}$ rate) similar to $6 \mathrm{~h}-\mathrm{HEMM}$ and 24-HEMM samples. This indicates that even PBM + HEMM samples cannot avoid mechanical degradation followed by side reactions when they are subjected to high C-rates. As shown in Figures 11e and 11f, particle-level degradation such as cracking, and electrode-level degradation such as delamination, were both observed in PBM + HEMM samples after 150 cycles at a high C-rate. This is because high current density severely disrupts current distribution homogeneity, eventually resulting in uneven expansion/contraction and local stress concentration on BP-G particles. The PBM + HEMM sample did, however, show higher initial reversible capacity at $1000 \mathrm{~mA} / \mathrm{g}$ than the other samples, with the initial reversible capacity at $1000 \mathrm{~mA} / \mathrm{g}$ only slightly lower than that at $100 \mathrm{~mA} / \mathrm{g}$.

\section{Conclusions}

This work presents a comprehensive study of BP-G electrochemical performance (reversible capacity, first cycle efficiency, and capacity retention) considering the influence of material composition, FEC additive, HEMM synthesis parameters, and electrode loading. Results suggest that the cycle stability of BP-G composites is most significantly affected by material composition and electrode loading (material composition $>$ electrode loading $>$ FEC additive $>$ ballmilling time), while first cycle efficiency and reversible capacity are more dependent on ballmilling time and material composition (ballmilling time $>$ material composition $>$ electrode loading $\approx$ FEC additive). BP$\mathrm{G}$ composite with a high ratio of $\mathrm{BP}\left(\mathrm{BP}_{0.9} \mathrm{G}_{1}\right)$ demonstrated a dramatic capacity fade under all conditions that was not alleviated by controlling HEMM synthesis parameters or using FEC additive. Cycle performance of BP-G composite can only be stabilized with a lower ratio of BP, which mitigates the mechanical degradation induced by the volume change. Further improvements in cycle stability can be achieved by optimizing the HEMM synthesis process. While BP-G composition is critical for cycle stability, ballmilling time strongly affects the acti- vation of $\mathrm{BP}$ in $\mathrm{BP}-\mathrm{G}$ composites. It is important to optimize HEMM synthesis times accordingly to achieve a high reversible capacity in BP-G composite.

With these findings, an optimized BP-G synthesis approach that employs a combination of shaker-type and planetary-type ball milling modes is proposed. This approach yielded improved electrochemical performance of BP-G composite, with excellent reversible capacity $(2,285 \mathrm{mAh} / \mathrm{g})$ and superior cycle performance (capacity retention of $80 \%$ over 150 cycles). Despite these strides forward, however, alternate strategies to HEMM-based synthetic routes will be necessary to design BP-G composites with high C-rate capabilities.

This work contributes to our understanding of the electrochemical performance of HEMM-synthesized BP-G composites and its dependence on various factors. It illuminates potential causes for the significant differences in $\mathrm{P}-\mathrm{C}$ electrochemical performance reported in the literature. It also reveals correlations between HEMM synthesis processes and the electrochemical performance of BP-G composites, providing useful guidelines for developing better BP-based anode materials using HEMM synthesis in the future.

\section{Acknowledgments}

This work was supported by the Global Research Outreach program of the Samsung Advanced Institute of Technology. The authors gratefully acknowledge the support.

\section{ORCID}

Hosop Shin (D https://orcid.org/0000-0003-3583-1421

Wei Lu (1D https://orcid.org/0000-0002-4851-1032

\section{References}

1. C. Park and H. Sohn, Adv. Mater., 19, 2465 (2007).

2. J. Sun, H. Lee, M. Pasta, H. Yuan, G. Zheng, Y. Sun, Y. Li, and Y. Cui, Nat. Nanotechnol., 10, 980 (2015) 
3. J. Song, Z. Yu, M. L. Gordin, S. Hu, R. Yi, D. Tang, T. Walter, M. Regula, D. Choi, X. Li, A. Manivannan, and D. Wang, Nano Lett., 14, 6329 (2014).

4. Y. Kim, Y. Park, A. Choi, N. Choi, J. Kim, J. Lee, J. Ryu, S. Oh, and K. Lee, Adv. Mater, 25, 3045 (2013).

5. M. Dahbi, N. Yabuuchi, M. Fukunishi, K. Kubota, K. Chihara, K. Tokiwa, X. Yu, H. Ushiyama, K. Yamashita, J. Son, Y. Cui, H. Oji, and S. Komaba, Chem. Mater, 28, 1625 (2016).

6. L. Chen, G. Zhou, Z. Liu, X. Ma, J. Chen, Z. Zhang, X. Ma, F. Li, H. Cheng, and W. Ren, Adv. Mater, 28, 510 (2016).

7. L. Sun, M. Li, K. Sun, S. Yu, R. Wang, and H. Xie, J. Phys. Chem. C, 116, 14772 (2012).

8. J. Sun, G. Zheng, H. Lee, N. Liu, H. Wang, H. Yao, W. Yang, and Y. Cui, Nano Lett., 14, 4573 (2014)

9. H. Liu, Y. Du, Y. Deng, and P. Ye, Chem.Soc.Rev., 44, 2732 (2015).

10. M. Stan, J. Zamory, S. Passerini, T. Nilges, and M. Winter, J. Mater. Chem., A, 1, 5293 (2013).

11. C. Marino, L. Boulet, P. Gaveau, B. Fraisse, and L. Monconduit, J. Mater. Chem., 22 22713 (2012)

12. J. Qian, D. Qiao, X. Ai, Y. Cao, and H. Yang, Chem. Commun., 48, 8931 (2012).

13. L. Wang, X. He, J. Li, W. Sun, J. Gao, J. Guo, and C. Jiang, Angew. Chem. Int. Ed., 51, 9034 (2012).

14. Y. Wang, L. Tian, Z. Yao, F. Li, S. Li, and S. Ye, Electrochem. Acta, 163, 71 (2015).

15. J. Li, L. Wang, X. He, and J. Wang, ACS Sustainable Chem. Eng., 4, 4217 (2016).
16. T. Ramireddy, T. Xing, M. Rahman, Y. Chen, Q. Dutercq, D. Gunzelmann, and A. Glushenkov, J. Mater. Chem. A, 3, 5572 (2015).

17. M. Nagao, A. Hayashi, and M. Tatsumisago, J. Power Sources, 196, 6902 (2011).

18. W. Xia, Q. Zhang, F. Xu, H. Ma, J. Chen, K. Qasim, B. Ge, C. Zhu, and L. Sun, J. Phys. Chem. C, 120, 5861 (2016).

19. Y. Du, Y. Tang, and C. Chang, J. Electrochem. Soc., 163, A2938 (2016).

20. T. Tojo, S. Yamaguchi, Y. Furukawa, K. Aoyanagi, K. Umezaki, R. Inada, and Y. Sakurai, J. Electrochem. Soc., 165, A1231 (2018).

21. H. Shin, J. Zhang, and W. Lu, Electrochim. Acta, 309, 264 (2019).

22. Y. Chen, J. Gerald, L. Chadderton, and L. Chaffron, Appl. Phys. Lett., 74, 2782 (1999).

23. T. Ong and H. Yang, Carbon, 38, 2077 (2000).

24. M. Francke, H. Hermann, R. Wenzel, G. Seifert, and K. Wetzig, Carbon, 43, 1204 (2005).

25. N. Welham, V. Berbenni, and P. Chapman, J. Alloys and Compd., 349, 255 (2003).

26. Y. Kado, Y. Soneda, D. Horii, K. Okura, and S. Suematsu, J. Electrochem. Soc., 166, A2471 (2019).

27. J. Hart, N. Allan, and F. Claeyssens, Phys. Chem. Chem. Phys., 12, 8620 (2010)

28. H. Shin, J. Park, A. Sastry, and W. Lu, J. Electrochem. Soc., 162, A1683 (2015).

29. R. Janot and D. Guerard, Prog. Mater. Sci., 50, 1 (2005).

30. T. Yadav, R. Yadav, and D. Singh, J. Nanosci. Nanotechnol., 2, 22 (2012).

31. F. Claeyssens, G. Fuge, N. Allan, P. May, and M. Ashfold, Dalton Trans., 0, 3085 (2004).

32. F. Claeyssens, Phys. Rev B, 79, 134115 (2009). 